\title{
PENGENALAN SASTRA ANAK UNTUK MENINGKATKAN LITERASI BACA TULIS ANAK
}

\author{
Intan Rawit Sapanti \\ Universitas Ahmad Dahlan, Yogyakarta, Indonesia \\ e-mail: intanrawit.sapanti@idlitera.uad.ac.id \\ Tristanti Apriyani \\ Universitas Ahmad Dahlan, Yogyakarta, Indonesia \\ e-mail: tristanti.apriyani@idlitera.uad.ac.id \\ Resneri Daulay \\ Universitas Ahmad Dahlan, Yogyakarta, Indonesia \\ e-mail: resneri.daulay@enlitera.uad.ac.id
}

\begin{abstract}
The low literacy of children in Indonesia is quite alarming because it can affect the competence of critical thinking, creativity, communication and collaboration that Indonesian children should have. One of the effective ways to ensure that the $4 \mathrm{C}$ competency mastery is achieved is by improving and fostering the reading literacy skills of Indonesian children. The purpose of this community service activity is to introduce children literature to children with the aim of increasing their interest in reading and literacy from an early age. It is hoped that in the future, by knowing and reading various literary works, moral values and the cultivation of good character can be given to children. By carrying out this training, it is hoped that students can produce a simple children's work / story in the form of an anthology work. The method of implementing this activity is divided into three stages, namely; the preparation stage, the implementation stage, and the final reporting stage. This activity involved two students, namely Rida Alifia (Indonesian Literature Department) and Andini Mandala Putri (English Literature Department). The community service activity partner is SD Negeri Gentan, and community service activity is conducted in SD Negeri Gentan on 21 November 2020, 28 November 2020, 5 December 2020 and 12 December 2020 through zoom meeting online. This activity was attended by 47 students of SD Negeri Gentan and was very well appreciated by the students and teachers. Students can listen well to 4 children's stories submitted by team members. They are able to answer well and retell the contents of the children's stories. The targets and outputs of this community service activity are scientific publication manuscripts published in journals, articles published in print media, activity videos, and IPR certificates. The output target that has been achieved is the production of children's story videos that have been uploaded on the YouTube channel of the Indonesian Literature Study Program, while other output targets such as publication texts and IPR certificates are in process.
\end{abstract}

Keywords-Children literature, literacy, character development 


\section{PENDAHULUAN}

Tahun 2012 United Nations Educational Scientific and Cultural Organization (UNESCO) pernah melakukan survey minat baca masyarakat Indonesia dan ditemukan hasil indeks minat baca masyarakat Indonesia baru mencapai angka 0.001 . Hal ini menunjukkan bahwa dari 1000 orang Indonesia hanya 1 orang saja yang memiliki minat baca. Tahun 2015 hasil penelitian Program for International Student Assessment (PISA) rilisan Organisation for Economic Co-Operation and Develompent (OECD) tahun 2015 terhadap 72 negara (540 responden) menunjukkan bahwa tingkat literasi anak-anak Indonesia usia 15 tahun dinilai cukup rendah. Indonesia menduduki peringkat 62 dari 65 negara yang teliti.

Kedua hasil penelitian ini cukup menarik perhatian pemerintah Indonesia karena ternyata literasi dan minat baca rakyat Indonesia khususnya anak-anak cukup mengkhawatirkan. Rendahnya kemampuan literasi ini dapat mempengaruhi kemampuan kompetensi berfikir kritis, kreativitas, komunikasi dan kolaborasi (Critical Thinking, Creativity, Communication and Collaboration), yang seharusnya dimiliki anak-anak Indonesia. Salah satu cara efektif untuk menjamin tercapainya penguasaan kompetensi 4C tersebut adalah dengan menumbuhkan dan meningkatkan kemampuan literasi baca anak-anak Indonesia.

Akan tetapi ada beberapa kendala dalam mengajak anak-anak Indonesia untuk mau dan gemar membaca. Interaksi yang ditawarkan media elektronik dan media digital ternyata lebih menarik perhatian anak-anak daripada interaksi dengan buku-buku bacaan. Padahal banyak hasil penelitian menunjukkan dampak negatif yang ditimbulkan dari interaksi tersebut. Dampak negatif ini tidak hanya menghalangi perkembangan kepribadian anak akan tetapi dapat menghambat perkembangan otak anak-anak.

Oleh karena itu diperlukan solusi agar anak-anak lebih menyukai berinteraksi dengan buku-buku bacaan salah satunya dengan memperkenalkan sastra kepada anak-anak. Berbagai penelitian telah membuktikan bahwa bahwa sastra dapat mengajarkan karakter yang baik, menanamkan nilai akhlak, dan budi pekerti. Seperti yang dikemukakan Samani dan Hariyanto (2016:112) pembentukan karakter siswa terbentuk dari salah satu jenis pengalaman belajar yang dibangun melalui intervensi dan habituasi. Pengalaman belajar Intervensi diterbentuk dari pengalaman belajar yang terstruktur. Sementara pengalaman belajar habituasi diciptakan dari situasi dan kondisi yang memungkinkan seseorang membiasakan diri berperilaku sesuai nilai yang menjadi karakter dirinya. Oleh karena itu, melalui pengenalan sastra anak diharapkan terbentuk pengalaman belajar intervensi dan habituasi.

Nurgiyantoro (2016) menyebutkan bahwa sastra anak adalah sastra yang secara emosional psikologis dapat ditanggapi dan dipahami oleh anak. Sastra anak berangkat dari fakta konkret yang dapat diimajinasi. (Nurgiyantoro, 2016) Sarumpaet (2010) mengemukakan bahwa sastra anak adalah sastra terbaik yang dibaca anak dengan karakteristik, tema, dan format yang beragam (Sarumpaet, 2010). Menurut Huck (1987) tidak perlu mempermasalahkan siapa yang menulis sastra anak, asalkan dalam penggambarannya menekankan kehidupan anak yang sarat akan nilai dan makna. (Huck, 1987). 
Berdasarkan pernyataan Huck tersebut Nurgiyantoro (2004) mendefinisikan buku sastra anak sebagai buku yang menempatkan sudut pandang anak sebagai pusat penceritaan, dikonsumsi anak sesuai dengan dunia, minat, perkembangan emosional, perkembangan intelektual anak-anak (Nurgiyantoro, 2004:107 - 122). Dapat disimpulkan bahwa sastra anak merupakan salah satu karya sastra ditulis dan dikonsumsi anak-anak. Sebagai karya sastra pada umumnya, sastra anak juga memberikan informasi dan pemahaman tentang kehidupan kepada anak.

Beragamnya dampak virtual mendorong perlunya karya sastra anak yang baik, menyentuh dan dapat dijadikan pelajaran serta teladan bagi anak. Kandungan akan nilai karakter yang baik dalam karya sastra anak, hendaknya dapat dibaca anak. Sejalan dengan yang dikemukakan Sarumpaet (2010) bahwa karya sastra yang berpihak pada anak bukan merupakan karya sastra yang memaksa dan mengatur, tetapi hendaknya yang dapat menyelami dan memahami pikiran dan kondisi anak. Buku sastra anak yang baik hendaknya mengandung nilai-nilai kehidupan yang dapat membangun jiwa anak dan mendorong pribadi anak menjadi pribadi yang jujur, rendah hati, pandai, mandiri, bertanggung jawab, dan berdisiplin tinggi.

Oleh karena keterbatasannya dalam memilih buku bacaan, seorang anak akan membaca bacaan apa pun yang ditemuinya tanpa memperhatikan cocok atau tidaknya bacaan tersebut baginya. Orang tua atau orang dewasa sekitarnya lah yang harus peduli terhadap bacaan yang akan dibaca anak sebab bacaan yang yang tepat dan sesuai dengan anak, akan mendorong tumbuh dan berkembangnya pribadi anak. Kehati-hatian juga diperlukan dalam pemilihan buku bacaan anak. Menurut Edwards (2004:89) pemilihan bacaan perlu mempertimbangkan faktor budaya karena anak tumbuh kembang dan belajar tidak dalam kevakuman budaya, akan tetapi anak dibesarkan dan diajarkan oleh keluarganya dalam adat istiadat, kebiasaan, perilaku dan sebagainya.

Usaha untuk memperkenalkan sastra anak disinyalir dapat menumbuhkan budaya literasi baca tulis pada anak-anak. Ketika membaca sastra anak, anak-anak akan diajak untuk berimajinasi melalui tokoh cerita tentang pengalaman-pengalaman baru yang sesuai dengan sudut pandang anak. Kebiasaan membaca ini nantinya akan mendorong minat anak untuk menulis.

Usaha untuk memperkenalkan dan mensosialisasikan sastra anak ini sejalan dengan rencana induk pengabdian masyarakat Fakultas Sastra, Budaya, dan Komunikasi bidang Sastra, program pelatihan minat dan bakat sastra. Dalam rencana induk pengabdian tersebut tertera bahwa kegiatan memperkenalkan dan mensosialisasikan sastra anak adalah untuk menanamkan kecintaan terhadap dunia sastra pada anak-anak.

Berdasarkan hasil survey melalui google form dan hasil wawancara dengan mitra PKM yaitu SD Negeri Gentan, Ngaglik, Sleman, Yogyakarta, ditemukan beberapa permasalahan terkait dengan situasi di atas;

a) Terdapat $93,5 \%$ siswa suka membaca.

b) Terdapat $51,1 \%$ responden menjawab jarang membaca dan 48,9\% sering membaca. 
c) Intensitas membaca sebanyak $62.2 \%$ menjawab sehari satu kali membaca, dan 37,8 seminggu sekali membaca.

d) Sekitar $39.1 \%$ responden menyatakan telah membaca lebih dari 5 buku, $17,4 \%$ membaca lebih dari 10 buku, 21,7\% telah membaca 3 buah buku, $17,4 \%$ telah membaca 2 buah buu dan sisanya 4,4\% membaca 0 buku.

e) Jenis buku yang disukai 15 siswa $(32,6 \%)$ adalah cerita legenda, cerita hewan disukai oleh 24 siswa $(52,2 \%)$, cerita petualangan disukai 16 siswa (34,8\%), komik disukai oleh 22 siswa $(47,8 \%)$, cerita horror disukai oleh 9 siswa (19,6\%) dan cerita komedi/lucu disukai oleh 12 siswa (26.1 $\%)$.

f) Beberapa alasan mengapa siswa suka membaca; asik, seru, lucu, menarik, menambah wawasan, ilmu pengetahuan, hiburan dan ceritanya bagus.

g) Beberapa alasan siswa tidak suka membaca karena $74 \%$ tidak ada gambar, tidak menarik/membosankan $(16,1 \%)$ dan lebih suka main game online sebanyak $9.7 \%$.

Mengacu temuan di atas, maka optimalisasi literasi baca tulis melalui pengenalan sastra anak kepada siswa SD Negeri Gentan, Ngaglik, Sleman, Yogyakarta, perlu untuk dilakukan. Situasi pandemi covid seperti ini mendorong pengenalan sastra dilakukan secara daring, yaitu dengan mengemas sastra anak ke dalam bentuk video.

\section{METODE}

Kegiatan pengabdian ini dilaksanakan di SD Negeri Gentan, Ngaglik, Sinduharjo, Sleman, Yogyakarta yang terletak di Jalan Kaliurang Km 10. Peserta pengabdian ini adalah siswa kelas 4, 5 dan 6 dengan rentang umur 9-11 tahun. Kegiatan ini pengabdian ini bertujuan untuk mengenalkan sastra anak melalui video cerita yang diharapkan dapat menumbuhkan minat dan ketertarikan terhadap sastra anak. Adapun solusi yang ditawarkan dari program pengabdian ini adalah:

1. Mengenalkan sastra anak melalui video cerita berbahasa Indonesia (Kue Pukis untuk Nenek \& Mencari Ujung Pelangi) dan cerita berbahasa Inggris (Bawang Merah and Bawang Putih, The turtle and the rabbit) kepada siswa SD Negeri Gentan.

2. Mengarahkan anak untuk melakukan apresiasi sastra dengan menyimak karya sastra, mengulas karakterisasi, alur cerita dan mengupas nilai-nilai moral atau amanah dalam cerita.

Selain itu, terdapat beberapa metode yang ditawarkan dalam kegiatan pengabdian ini. Metode tersebut antara lain:

1. Melakukan riset/survey sederhana melalui gform di awal untuk mengetahui tingkat atau minat membaca anak-anak di SD Negeri Gentan.

2. Berkomunikasi secara langsung untuk mengukur tingkat pemahaman mereka terhadap karya sastra.

3. Mengenalkan sastra anak dan judul-judul buku yang menarik.

4. Melakukan diskusi secara online melalui aplikasi Zoom. 


\subsection{Tahapan Review}

Evaluasi pelaksanaan kegiatan pelatihan ini diuraikan dalam tabel 1 berikut:

Tabel 1. Evaluasi Pelaksanaan Kegiatan

\begin{tabular}{|l|l|l|}
\hline Tujuan & Indikator Ketercapaian & Tolak Ukur \\
\hline $\begin{array}{l}\text { Peserta pelatihan } \\
\text { mengenal sastra anak }\end{array}$ & $\begin{array}{l}\text { Peserta mengenal karya } \\
\text { sastra anak }\end{array}$ & $\begin{array}{l}\text { Peserta mengetahui } \\
\text { karya sastra anak dalam } \\
\text { 2 cerita Bahasa } \\
\text { Indonesia dan 2 cerita } \\
\text { Bahasa Inggris }\end{array}$ \\
\hline $\begin{array}{l}\text { Peserta pelatihan dapat } \\
\text { memahami materi } \\
\text { apresiasi sastra }\end{array}$ & $\begin{array}{l}\text { Peserta dapat } \\
\text { memahami apresiasi } \\
\text { sastra }\end{array}$ & $\begin{array}{l}\text { Peserta dapat } \\
\text { memahami materi } \\
\text { apresiasi sastra dengan } \\
\text { baik (plot, alur, } \\
\text { karakterisasi, amanah) }\end{array}$ \\
\hline
\end{tabular}

\section{1.1 Gambar dan tabel}

Berikut merupakan dokumentasi pengabdian yang dilakukan secara online melalui media Zoom
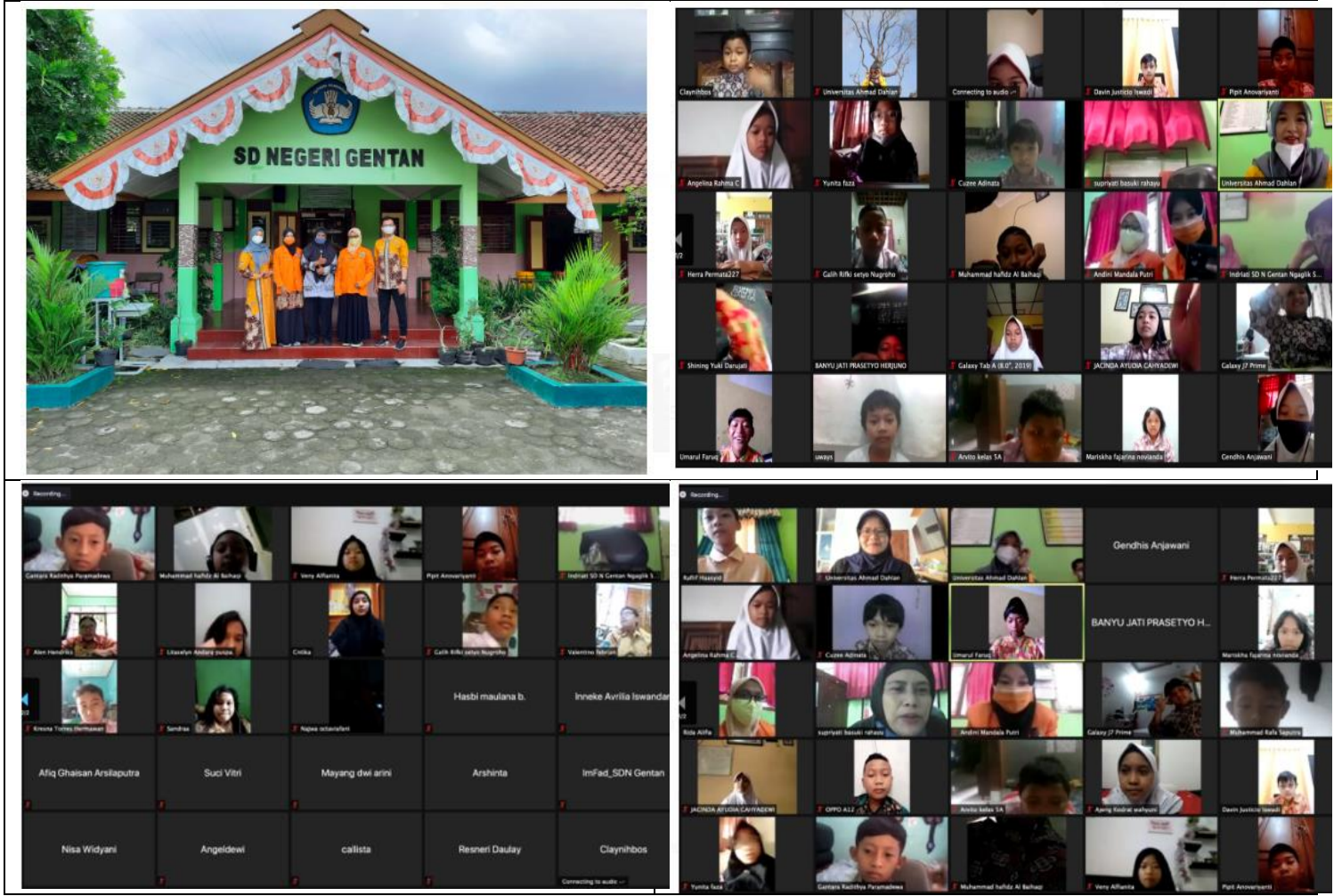

Gambar 1 Kegiatan Pengabdian 


\subsection{Keberlanjutan Kegiatan}

Keberlanjutan kegiatan pengabdian ini bertujuan agar siswa SD Negeri Gentan mengenal karya sastra anak dan mampu mengapresiasi karya sastra dengan baik. Kegiatan ini perlu dilakukan secara berkala agar secara bertahap siswa dapat tertarik untuk mengenal karya sastra sehingga memiliki ketertarikan untuk membaca karya sastra. Peran orang tua juga sangat penting dalam menumbuhkan ketertarikan membaca, misalnya orang tua dapat membacakan cerita/dongeng sebelum tidur dan melakukan apresiasi sastra dengan berdiskusi dengan anak tentang alur cerita, karakterisasi dan nilai-nilai moral yang terkandung dalam cerita tersebut. Pelaksanaan kegiatan pengabdian ini memang dirasa belum cukup mengingat kondisi pandemik Covid 19 yang tidak memungkinkan pengabdian dilaksanakan secara langsung. Oleh sebab itu kegiatan ini diharapkan dapat dilakukan secara berkelanjutan, tentunya dengan melihat situasi dan kebutuhan para siswa SD Negeri Gentan.

\section{HASIL DAN PEMBAHASAN}

Kegiatan pengabdian ini dilakukan sebanyak 4 kali pertemuan. Pada pertemuan pertama dan kedua dilakukan pembacaan cerita sastra anak dan proses perekaman cerita dan editing menjadi video yang diunggah di channel youtube prodi Sastra Indonesia. Pada pertemuan ketiga dan keempat tim pengabdi memberikan pelatihan yang diikuti oleh 46 siswa SD N Gentan. Pada kegiatan ini, seluruh peserta mendengarkan arahan dari kepala sekolah dan tim pengabdi dengan seksama.

Hasil pengabdian berupa pelatihan ini akan tampak pada ketertarikan anak kepada sastra anak dan kemampuan dalam mengapresisasi sebuah karya sastra. Saat tim pengabdi menayangkan video cerita sastra anak dalam Bahasa Inggris dan Bahasa Indonesia, para siswa tampak antusias dalam menyimak cerita yang dibawakan oleh anggota tim. Para siswa juga aktif dan antusias menjawab pertanyaan terkait karya sastra yang disampaikan. Hal ini membuktikan bahwa cerita sastra anak mampu menarik perhatian siswa SD Negeri Gentan, Yogyakarta. Meskipun kegiatan ini dilaksanakan secara daring melalui media zoom namun tidak mengurangi antusiasme para siswa dalam mengikuti kegiatan ini.

Melalui cerita kue pukis untuk nenek, para siswa diajak untuk mengingat kembali makanan kesukaan nenek, hal-hal apa yang telah dilakukan untuk menyenangkan hati nenek, kapan terakhir kali mengunjungi nenek dan apakah para siswa sudah menjaga dan merawat nenek dengan baik. Para siswa tampak antusias dalam memberikan jawaban mengenai makanan kesukaan nenek dan hal-hal yang menunjukkan kedekatan mereka dengan neneknya. Melalui cerita Mencari Ujung Pelangi, para siswa diajak untuk memiliki kesadaran untuk dapat menjaga lingkungan alam sekitar dengan melestarikan penanaman pohon, tidak membuang limbah dan mencemari lingkungan. Para siswa dapat dengan lancar menceritakan kembali isi cerita tersebut. Padahal cerita Mencari Ujung Pelangi tergolong cerita yang cukup Panjang dibandingkan dengan cerita Kue pukis untuk nenek.

Cerita anak berbahasa Inggris pun turut diperkenalkan kepada para siswa. Cerita The turtle and the Rabbit yang disampaikan dalam bahasa Inggris cukup

menarik perhatian para siswa. Cerita ini membawa pesan moral untuk tidak 
merendahkan lawan dan bersikap sportif, tidak boleh lengah dan terus berusaha. Nilai-nilai moral inilah yang harus ditanamkan dan dipraktikkan dalam kehidupan sehari-hari. Meski dikemas dalam cerita berbahasa Inggris, para siswa tetap antusias terbukti dengan tidak adanya siswa yang meninggalkan arena zoom dan aktif menjawab beberapa pertanyaan yang dilontarkan. Dalam hubungannya dengan pembelajaran, khususnya literasi baca tulis, maka dapat dikatakan bahwa pengenalan sastra anak melalui video ini mampu meningkatkan ketertarikan siswa terhadap karya sastra anak.

\section{KESIMPULAN}

Berdasarkan seluruh uraian di atas dapat dikatakan bahwa pengenalan sastra anak terbukti dapat meningkatkan literasi Baca tulis anak. Siswa dapat tampak memahami arti budaya literasi. Hal ini dibuktikan dengan antusiasnya siswa dalam menyimak dan mencernati setiap karya sastra yang ditampilkan serta dapat mengapresiasi karya sastra anak tersebut dengan baik.

Literasi baca tulis akan dapat terlaksana optimal jika tersedianya sarana dan prasarana yang memadai, nyaman, ramah dan menyenangkan bagi anak. Dilakukannya pembiasaan siswa dalam kegiatan membaca sastra anak disinyalir dapat meminimalisir dampak negatif dari penggunaan gawai.

\section{SARAN}

Menyadari akan pentingnya uraian di atas, mendorong sekolah mitra untuk dapat menerapkan dan mengoptimalisasikan budaya literasi baca tulis melalui sastra anak. Beberapa saran yang dapat disampaikan adalah pertama, sekolah hendaknya dapat memfasilitasi kegiatan budaya literasi baik di kalangan siswa maupun guru dan tenaga pendidik. Kedua, perlu adanya pelatihan bagi guru-guru untuk dapat menyiapkan bacaan sastra anak dan membimbing siswa saat kegiatan literasi. Sementara itu, pemerintah diharapkan dapat responsif terhadap menurunnya minat baca anak akibat dampak dari penggunaan gawai. Pemerintah dinilai perlu dilakukan pendataan secara menyeluruh terhadap perpustakaan setiap sekolah dasar agar kualitas perpustakaan dapat terpantau secara maksimal. Dengan melakukan pendataan pemerintah pun dapat memetakan kebutuhan bantuan pengadaan perpustakaan tepat sasaran.

\section{UCAPAN TERIMA KASIH}

Ucapan terima kasih kami sampaikan kepada Kepala Sekolah SD Negeri Gentan Ibu Supriyati Basuki Rahayu, S.Pd., M.Pd. yang telah memberikan dukungan penuh sehingga kegiatan pengabdian ini dapat terlaksana dengan baik dan lancer. Ucapan terima kasih juga kami sampaikan kepada kepala LPPM UAD Bapak Anton Yudhayana, S.T., M.T., Ph.D yang telah mendukung dan memberi kami kesempatan untuk melaksanakan kegiatan pengabdian masyarakat ini. Besar harapan kami agar dapat melaksanakan kegiatan pengabdian ini secara berkelanjutan di masa mendatang. 


\section{DAFTAR PUSTAKA}

Nurgiyantoro, B. (2016). Sastra Anak: Pengantar Dunia Anak. Yogyakarta: UGM Press.

Sarumpaet, R. T. (2010). Pedoman Penelitian Sastra Anak. Jakarta: Yayasan Obor Indonesia.

Huck, C. S. (1987). Children Literature in the Elementary School. New York: Holt Rinehart.

Nurgiyantoro, B. (2004). Sastra anak: persoalan genre. Jurnal Humaniora, 16 No 2, $107-122$.

Edwards, P. A. (2004). Children's Literary Development. Boston: Pearson.

Samani, M., \& Hariyanti. (2016). Konsep dan Model Pendidikan Karakter. Bandung: Remaja Rosdakarya. 